\title{
After Fukushima: The precautionary principle revisited
}

\author{
Author: \\ Wolfgang Huber ${ }^{1,2,3,4}$ \\ Affiliations: \\ ${ }^{1}$ Fellow of the Stellenbosch \\ Institute for Advanced Study \\ (STIAS), Stellenbosch, \\ South Africa \\ ${ }^{2}$ Faculty of Theology, \\ Humboldt University of \\ Berlin, Germany \\ ${ }^{3}$ Faculty of Theology, \\ University of Heidelberg, \\ Germany \\ ${ }^{4}$ Research associate, \\ Department of Dogmatics \\ and Christian Ethics, \\ University of Pretoria, \\ South Africa \\ Correspondence to: \\ Wolfgang Huber \\ Email: \\ sekretariat@wolfganghuber \\ info \\ Postal address: \\ Stellenbosch Institute for \\ Advanced Study (STIAS), \\ Wallenberg Research Centre, \\ Stellenbosch University, \\ Marais Street, Stellenbosch \\ 7600 , South Africa \\ Dates: \\ Received: 03 May 2012 \\ Accepted: 07 June 2012 \\ Published: 06 Dec. 2012 \\ How to cite this article: \\ Huber, W., 2012, \\ 'After Fukushima: The \\ precautionary principle \\ revisited', Verbum et Ecclesia \\ 33(2), Art. \#736, 6 pages. \\ http://dx.doi.org/10.4102/ \\ ve.v33i2.736
}

C 2012. The Authors. Licensee: AOSIS OpenJournals. This work is licensed under the Creative Commons Attribution License.
Etienne de Villiers, more than other theologians, elaborates on basic elements of a Christian ethics of responsibility. He distinguishes between retrospective and prospective responsibility. The prospective aspect attracted awareness after the nuclear accident in the Fukushima reactors on 11 March 2011. The question on how to respond in an ethically responsible manner to catastrophic risks was put back on the agenda. The article takes up this question and discusses the answer given in the international debate by the introduction of the 'precautionary principle'. The principle is described with its background in the 'heuristics of fear', proposed by the philosopher Hans Jonas. Four criticisms are discussed in detail relating to the problems of scientific uncertainty, the burden of proof, the weight of damages and the perils of precaution. That leads to a reformulation of the precautionary principle as a concrete element within an ethics of responsibility.

\section{Ethics of responsibility}

Like no other theologian, Etienne de Villiers discussed over the last number of years the ways in which Christian theology has taken up newer debates on an ethics of responsibility (see De Villiers $2002,2003,2006,2007 a, 2007 b, 2010,2011 a, 2011 b)$. He analyses the importance as well as the limits of Hans Jonas' The Imperative of Responsibility (Jonas 1979, 1984) for the development of an ethics of responsibility in philosophy as well as in theology. He comes to the clear conclusion that responsibility is not, as Jonas proposes, a basic ethical principle in itself but that it presupposes an idea of the ethically good. Likewise, De Villiers emphasises that ethics are not to be restricted - as in the case of Jonas - to the question of possible future consequences of present actions.

Therefore De Villiers warns not to introduce, following Jonas, a too narrow concept of responsibility into Christian ethics. However, he gives good reasons why one could still work with this concept in ethics. He observes that the move of the ethical language from 'duty' to 'responsibility' is not coincidental but indicates a fundamental change in the understanding of moral obligations that relates not simply to external norms but to convictions accepted by the responsible person herself. He includes Jonas' proposal into a broader concept insofar as the new challenges of modern technological developments make it necessary to supplement the notion of retrospective responsibility by the notion of prospective responsibility. Whereas in the case of retrospective responsibility, events in the past and their consequences are attributed to a person or to persons, prospective responsibility relates to the task of preventing humans and nature from being harmed in the future by present actions and of providing by present actions desirable future conditions for the life of humans and nature. It further ascribes this task to a person or persons or to an institution or institutions (De Villiers 2002).

Following De Villiers, we have to bear in mind the warning not to isolate the aspect of prospective responsibility. We rather need to enlarge the ethical perspective and to take into consideration the future effects of present actions. This was not only proposed by Has Jonas, but already six decades before him, the sociologist Max Weber proposed the same under the title of an ethics of responsibility (Weber 1994). Today, specific challenges make an elaboration on this aspect of an ethics of responsibility urgent. When I try to contribute to this task with the following pages, I do so in deep gratitude to Etienne de Villiers for his continuous work on this important issue and for his personal friendship.

\section{On rational responses to catastrophic risks}

On 28 February 2011, Evelyn Fox Keller, the well-known physicist and professor for history and philosophy of science at Massachusetts Institute of Technology (MIT) and then fellow at the Stellenbosch Institute for Advanced Study (STIAS), presented a STIAS lecture on the topic: 'What is a rational response to catastrophic risk?' (Fox Keller 2011). The main catastrophic risk Evelyn Fox Keller discussed in her reflections was global warming. Her criticism was directed towards the 
fact that many experts do not take climate change seriously enough. She feared that a limitation of global warming to two degrees Celsius had already become unreachable, and she asked how the community of experts contributed to that development.

Therefore, she discussed the question whether or not the expertise of the experts is the only way to obtain a realistic anticipation of possible events in the future. For the distinction between the different ways in which experts and ordinary people address those future events, she followed Gerd Gigerenzer, a researcher at the Max Planck Institute for Human Development in Berlin, in using a stunning example (Gigerenzer 2007).

The example refers to a ball player catching a ball. Richard Dawkins (1976), in his famous book The Selfish Gene, offered a description of how a ball player catches a ball:

When a man throws a ball high in the air and catches it again, he behaves as if he has solved a set of differential equations in predicting the trajectory of the ball. He may neither know nor care what a differential equation is, but this does not affect his skill with the ball. At some subconscious level, something functionally equivalent to the mathematical calculations is going on. (p. 6)

Evidently Dawkins follows a monistic epistemology and therefore assumes that the ball player performs differential equations, otherwise he would not be able to catch the ball. This assumption, however, is in a striking contrast with how ball players actually proceed. As Gerd Gigerenzer explains, ball players do not calculate the ball's trajectory; they use different heuristics that are both easier and more effective. Amongst others, they use what Gigerenzer calls the 'gaze heuristics'.

The gaze heuristics are a stunningly simple rule of thumb that enables the player to be at that precise spot just when the ball lands (and hence to catch the ball), but it does not enable him or her to predict where it will land. It requires nothing more than fixing one's eye on the ball when it is high and running in a direction that maintains a constant angle between the line of sight and the ground as it comes down. This gaze heuristic does not require differential equations but refers only to the fact of gravity that is built into the adaptive capacities of every human being.

As the example shows, it would not be correct to call the gaze heuristics emotional and to call only the use of differential equations rational. Rather the gaze heuristics has its own rationality - a rationality that has to do with processes in which we are involved. Therefore, we ask ourselves whether we shall be at the right spot before the ball lands.

Evelyn Fox Keller applies this insight to the question: What kind of anticipations of the future has to be taken seriously? She proposes to take anticipations that follow a 'gaze heuristics' as seriously as those following the 'differential equation' or other forms of expert calculations. She expects rational anticipations from both ordinary people and experts. In this way, she rehabilitates a philosophical proposal going back to Hans Jonas' Imperative of Responsibility (Jonas 1979, 1984). At the centre of this book stands a new categorical imperative. Instead of Kant's categorical imperative that obliges us to prove whether the maxim of our action can be made into a generalised or universal law, Jonas proposes as categorical imperative: 'Act so that the effects of your action are compatible with the permanence of genuine human life' (Jonas 1984:11).

Such an imperative presupposes, on the one hand, a duty to contribute to the permanence of genuine human life. Although Jonas declares that he does not want to refer to religious ethics but prefers to rely on a philosophy of nature that bridges the 'chasm between scientifically ascertainable "is" and morally binding "ought"' (Jonas 1984:X), he nevertheless returns to the 'sanctity of life' (Jonas 1984:26) as the decisive reference point for his categorical imperative. He uses for that purpose an interesting kind of implicit or 'negative' theology following the Jewish idea that God as creator restricts himself from intervening in his creation and respects the freedom with which he endowed it (Jonas 1987). Evidently Jonas extends to the future the commandment not to kill or more generally the ethical principle not to do harm. Etienne de Villiers rightly clarifies that there is no difference whether the imperative not to harm is applied to the present or to the future.

Jonas' imperative obliges, on the other hand, one to anticipate the (possible) effects of your actions in the future. Therefore, Jonas asks for a 'predictive science of the long-range effects of technological action' (Jonas 1984:27ff.). The problem is that this predictive science depends on a heuristics that helps science to know what it is searching for. Human beings know about the sanctity of life only because they experience that they are able to execute deadly violence against each other. In this sense, the dispute between Cain and Abel is prior to the explicit knowledge about the commandment not to kill. Human beings know the value of truth only because they are aware of lies. They develop an ethics of responsibility for distant contingencies only because they know what they fear. The perception of what to avoid is a necessary precondition to understand what kind of precaution has to be taken. This precaution has to take into consideration the possible effects of present actions that endanger the prospects of human life. Jonas firmly argues in this context for the prevalence of the bad over the good prognosis. He does not follow a philosophy of hope that gives priority to the good prognosis but a philosophy of responsibility that obliges on to avoid actions that in their consequence could endanger 'the permanence of genuine human life'.

It is important to notice at this point that Jonas does not favour a zero-risk-fantasy. On the contrary: It is the inevitability of risks that leads him to his heuristics of fear as well as to the imperative to avoid as many risks as possible that endanger the permanence of genuine human life. 
Jonas has in mind the difference between imminent or present dangers and distant or future dangers, between dangers with a high probability and dangers with a lower or unknown probability. Because his focus is on dangers that are relevant to the future of humankind, he argues to take seriously also the fears that relate to the distant future and to take them into account even if experts attribute to them only a low probability.

So his heuristics of fear imply already what was called only a few years after the publication of his book the 'precautionary principle' and what was in the following years mostly applied to environmental politics. The Rio de Janeiro Summit in 1992 defines the 'precautionary approach' in Principle 15 of its 'Agenda 21' as follows:

In order to protect the environment, the precautionary approach shall be widely applied by States according to their capabilities. Where there are threats of serious or irreversible damage, lack of full scientific certainty shall not be used as reason for postponing cost-effective measures to prevent environmental degradation. (United Nations General Assembly 1992)

And that indeed was also Evelyn Fox Keller's conclusion on 28 February 2011 in Stellenbosch. Following Jonas' 'heuristics of fear', she asked for 'new ways of thinking' that prepare us better than our usual expertise 'for actions that are appropriate to the threats we currently face'.

\section{Lessons from Fukushima}

Eleven days after Evelyn Fox Keller's STIAS-Lecture, 11 March 2011, an earthquake and a following tsunami hit the Japanese main island Honshu. The consequences of this natural disaster included especially the prefecture Fukushima in which a big nuclear power plant is situated. The strength of the earthquake exceeded the level of natural events for which this nuclear power plant was designed. Four of the six reactor blocs were destroyed. A core meltdown followed that set free radioactive materials to the amount of $10 \%$ $20 \%$ of the Chernobyl accident of 1986. Between 100000 and 150000 people were evacuated. The exact number of human casualties is unknown. Several hundreds of thousands of animals, left on the respective farms, died from hunger. Contamination and devastation will endure for decades. After some hesitation, the event was given the highest rank in the gravity of nuclear accidents, namely stage seven. An evaluation of the details showed that there were several early warnings that related to possible risks in the Fukushima reactors, but these risks were not taken seriously enough by the operating enterprise.

After the Chernobyl nuclear catastrophe in 1986, it was argued that it took place in a country - the Ukraine - in which general standards of security were not met. In more advanced industrial states, a comparable accident would therefore not happen. The Fukushima event nonetheless happened in a technologically highly advanced country. What is more, is that it happened in the country that, behind the USA and France, is number three amongst the leading producers of nuclear energy. Therefore, the argument that, in countries with many nuclear power plants, an event comparable with the Chernobyl accident could not happen had lost its credibility. A revision of views seemed to become necessary.

The debate on nuclear energy has been raging for decades now. Related to the discussions on global warming, it was argued that, in light of the policies on climate change, the use of nuclear energy would be unavoidable because no carbon dioxide is emitted through the production of nuclear energy. This perspective was, however, shattered by the Fukushima event. For countries with a high economic involvement in nuclear energy like the US or an extremely high dependency on nuclear energy like France (78\%), it is extremely difficult to correct their energy politics. Such a switch is incomparably easier for countries where nuclear energy contributes to only a small percentage of the general energy supply. Examples of the latter are China with $2 \%$ or South Africa with $5 \%$ from its single nuclear power plant with two reactors in Koeberg near Cape Town. I wonder how the debate in South Africa will develop further after its formal commitment to a Green Economy Accord in November 2011 where the emphasis is on energy efficiency, renewable energy and a low carbon economy. Things are quite different in Japan, which has, behind France, the highest dependency on nuclear energy in the world, that is $30 \%$. The fact that it is the same country where the first nuclear bombings were exerted in 1945 provides an additional tragic commentary on the Fukushima event and forms an serious background for the ongoing debate over nuclear energy in Japan.

In Germany, the dependency on nuclear energy is a little bit lower than in Japan, namely $23 \%$. In the German case, the irony is that, in 2000, the then government came to a 'nuclear consensus' with the goal to terminate the use of nuclear energy in Germany at the beginning of the 2020s. In 2010, however, under obvious pressure of the energy industry, this consensus was revoked, and the time limits for the existing reactors were extended to the 2030s. Six months after this decision, the Fukushima accident happened. In a very quick response, Chancellor Angela Merkel decided to terminate the relatively old reactors, to organise a stress test for even the younger ones and to ask for the advice of an ad hoc Ethics Committee on Safe Energy Supply (see Ethikkommission Sichere Energieversorgung 2011).

Critical objections were raised against the founding of this Ethics Committee because it was expected to return to the earlier 'nuclear consensus' and to give an external authorisation for the revision of a decision for which the energy industry had lobbied very strongly. That is indeed what happened. The committee argued that the position of moderate advocates and radical critics of the use of nuclear energy could be reconciled by bringing an end to this form of energy supply in the early 2020s, exactly the date of the former 'nuclear consensus'. 
How much 'ethics' was behind this rather tactical advice? The committee's report develops at least two important ethical perspectives. The one has to do with the priority of energy efficiency and a careful use of energy over the debate on the different energy resources. The other has to do with the evaluation of future risk.

For the evaluation of future risks, experts normally 'assess the risk of some hazard by computing (a) the magnitude of the hazard, and (b) the probability that it will occur, and (c) multiplying the two numbers together' (Fox Keller 2011:1). A consequence of this kind of mathematical calculation may be that hazards with limited magnitude but high probability are calculated as more important than high risks with low probability. This kind of calculation is justified by the argument that zero risk is in any case impossible.

The debate on nuclear energy followed this line to a great extent, putting aside the open question of the safe, permanent storage of radioactive material over an unimaginable long time. The German Ethics Committee on Safe Energy Supply argued that high risks, even in the case of a comparably low probability, can be valued with a high priority in the political decision-making process. It is not less rational, the Committee argued, to put the extent of a possible catastrophe in the centre of political awareness than to assess the risk by multiplying its magnitude with the probability that it will occur (Ethikkommission Sichere Energieversorgung 2011:2936). That meant, at the same time, that the assessment of future risks lies not only in the hands of experts applying their kind of mathematical calculation but also in the hands of an informed public that judges from an ethical perspective the risks that are at stake. It is also not irrational when political decisions take into account such a deliberative process together with the information provided by experts.

\section{Controversies around the precautionary principle}

The German Ethics Committee on Safe Energy Supply gave the precautionary principle a specific turn and argued for the preferential option to avoid high risks even if only a low probability is attributed to them. That leads us to a final discussion of some controversies around the precautionary principle itself.

\section{Scientific uncertainty}

The first formal statement on the precautionary principle can be found, as already mentioned, in Principle 15 of the Rio-Declaration of 1992. It was the same year in which the European Union included the precautionary principle into the treaty on the working procedures of the European institutions, the Maastricht Treaty of 1992. Its Article 130r states under No. 2:

Community policy on the environment shall aim at a high level of protection taking into account the diversity of situations in the various regions of the Community. It shall be based on the precautionary principle and on the principles that preventive action should be taken, that environmental damage should as a priority be rectified at source and that the polluter should pay. (European Union 1992)

As at the same time, in Principle 15 of the Rio Summit and also in the Maastricht Treaty (1992), the idea of scientific uncertainty plays a crucial role. The European Commission (2000) explained this aspect as follows some years later:

The precautionary principle applies where scientific evidence is insufficient, inconclusive or uncertain and preliminary scientific evaluation indicates that there are reasonable grounds for concern that the potentially dangerous effects on the environment, human, animal or plant health may be inconsistent with the high level of protection by the EU. (n.p.)

This strong emphasis on scientific uncertainty needs a commentary. In this specific context, scientific uncertainty has not only to do with the notorious fallibility of science or with the experience of continuous scientific self-revisions. In those cases to which the precautionary principle apply, scientific expertise relates to future events. With regard to the future, the uncertainty is different from that of science in general. Uncertainty concerning the future has to do with the modes of time - past, present and future - and the modalities of necessity, reality and possibility (see Picht 1980). Whereas the past is related to the modality of necessity and the present is related to the modality of reality, the future is related to the modality of possibility. Therefore, all scientific expertise on the future is expertise on the possible and therefore of an inherent uncertain nature.

However, there are scientific statements on the future with higher or lower probability. Therefore, all applications of the precautionary principle have to be open for revision. That is the case as far as scientific statements on the probability of future events play an important role. It is also the case as far as the 'heuristics of fear' or other kinds of 'gaze heuristics' are applied. In both cases, better insight can lead to a revision of previous judgments, or the progress of science and technology can lead to a new evaluation of risks and opportunities. Therefore, the precautionary principle has to be applied in a process which is open for revisions.

\section{The burden of proof}

To restrict the use of the precautionary principle to the aspect of scientific uncertainty seems to be too one-dimensional. Another aspect was put to the fore when the principle was explained from the perspective of the burden of proof. The Commission of the European Union, for instance, stated in 2000 that, in cases of the release of rays or toxins or in the case of massive clearance, the burden of proof lies with the proponents of those actions. The underlying argument seems to say that, in the case in which the 'heuristics of fear' argues for possible danger related to the development or the application of a new technology, the release of possibly dangerous substances or a grave intervention into the environment, the burden of proof lies not with those who state the danger but with those who propose the disputed activity. That creates the impression that the proponents of a 
new technology, a new vaccine or whatsoever have to prove that there is no risk involved.

The requirements set out in the previous paragraph would indeed lead to a self-contradictory result. Without arguing for a zero-risk concept in general, a proof for zero-risk would be required in every single case in which an interested group appeals to the precautionary principle. For that reason, Cass Sunstein, a legal scholar who became the administrator of the White House Office for Information and Regulatory Affairs under President Obama, strongly opposed the precautionary principle (Sunstein 2005). He criticises not only a tendency towards a zero-risk illusion but also the focus on the worstcase scenario independent of its probability.

At this point, a digression on the worst-case scenario should be added. It has to be remembered that the worstcase scenario originally was a strategic concept of military planning. The arms race during the Cold War was dictated on both sides by this scenario. Every side had to be prepared against a massive attack from the other side, including means of mass destruction. So every side wanted to have a secondstrike capability. A system of mutual assured destruction (MAD) was created.

In the war against terror, the United States of Amercia (USA) followed this tradition of worst-case thinking. United States (US) Vice-President, Dick Cheney, proclaimed in November 2001 the so called 1\% doctrine stating that, even in the case of a $1 \%$ possibility of a nuclear bomb being available to the alQa'ida terrorists, the US had to treat it 'as a certainty in terms of our response' (Fox Keller 2011:5; see Suskind 2006).

Sunstein evidently does not like to transfer this kind of idea to environmental politics. Instead, he reinforces a political atmosphere that uses worst-case scenarios in the field of terrorism but not with regard to climate change, environmental degradation or excesses on the financial markets. Therefore, he insists that regulatory policy, as he has to stand for in the White House, has to be based only on expert judgement, that is rationality, and not on popular sentiment, that is emotion.

With this he falls back onto a problematic alternative. Emotion can be found not only on the side of ordinary citizens but also on the side of experts. Furthermore, rationality is not only to be found on the side of 'differential equations' but also on the side of 'gaze heuristics'. Sunstein's criticism is nevertheless helpful insofar as it warns us not to fall into another equally wrong alternative, namely to put the burden of proof on either the proponents or the opponents of a certain activity. It rather seems that both perspectives have to be brought into a public discourse and into a transparent and participatory decision-making process. In the end, a political consideration on ethical grounds will have to decide which side will be given greater weight.

\section{The weight of damages}

Even under the assumption that the precautionary principle is applied, the procedure of experts would normally be, as described before, to calculate the mathematical expectation by multiplying the estimated magnitude of future risks with their estimated probability. Already the fact that we have to include estimations in both factors of this mathematical product makes clear that even this procedure with its pretended objectivity is to a high degree susceptible to subjective evaluations, to tendentious judgements, to the promotion of prejudices or even to emotions under the veil of objectivity. Therefore, it is necessary to clarify whether this is the only way of rational procedure. For that purpose, the most important point seems to be that every rational procedure has to be open for iterative processes, for self-critical evaluations and for the revision of previous results. Even in theories on economic decision making, the interconnectedness between irreversibility and uncertainty was introduced as a new aspect.

Under the conditions of uncertainty, a special kind of caution is needed with regard to actions with irreversible consequences. We have to add: This irreversibility has to do not only with the life conditions of present but also of future generations. Actions with irreversible consequences require a high degree of precaution, even if a high degree of uncertainty is involved (see Gollier, Jullien \& Treich 2000).

The interconnectedness between irreversibility and uncertainty is the reason why the heuristics of fear apply to actions with high risk even if only a low probability is assigned to them. As the German Ethics Committee on Safe Energy Supply stated, there is no imperative for a rational procedure that turns the mathematical expectancy of the available alternatives into the decisive point of reference for a final decision. It is a rational decision to categorise hazards with a higher magnitude and lower probability as more serious than hazards with a lower magnitude and higher probability. It is a question of public ethics that will determine which level of risk a society will take, for instance, for its energy supply. It is even more a question of public ethics that will determine which level of risk a society will take on behalf of the next generations.

\section{Perils of precaution}

The last point of criticism addresses the insight, from another angle, that there is no zero-risk society. The criticism was coined by Max More, a rather eccentric philosopher and partisan of Ray Kurzweil, into the precise formula of the 'perils of precaution' (More 2010). He presents a long list of achievements of science and technology that became possible only by way of taking risks. The list starts with A for airplane and Aspirin and presents at the end the vaccines for rabies, measles, polio and smallpox. Max More is convinced that, in all these cases, the fear of possible side effects would have alarmed the application of the precautionary principle and would eventually have hindered a breakthrough in scientific and technological progress. More states: 'The principle endangers us by trying too hard to safeguard us.' 
There may be some reasons to issue a warning about the excessive use of the precautionary principle. There is, for instance, an ongoing debate about whether or not the critique of green genetic engineering in some countries (like Germany) is exaggerated. However, this kind of debate has nothing to do with the principle itself but only with its reasonable application.

\section{Conclusion}

In the interpretation given in the precedent paragraphs, the precautionary principle is applicable if there are reasons to weight higher risks with a lower probability stronger than lower risks with a higher probability. In those cases, the uncertainty of the assessment of future risks has to be balanced with the irreversibility of possible effects. The consideration also has to take into account the possible benefits of a proposed activity and the possible achievements of new technologies or of a scientific progress. The lesson of Fukushima is that even a low probability of a core meltdown in a nuclear reactor provides reason for the search for alternatives to the use of those reactors for energy supply. The answer has, however, to take into account the effects of carbon dioxide on the global climate. Therefore, a careful use of energy, higher energy efficiency and renewable energy resources are preferable options.

The precautionary principle is not in itself a sufficient principle on which to take decisions. It is rather a regulative idea or a criterion under which proposed activities have to be considered and alternatives have to be developed. It expresses respect for the sanctity of life and for the life conditions of future generations. In this way, it applies to the technological era the imperative not to harm. It takes prospective responsibility seriously and searches for ways to sustainable development.

Since the Brundtland-Report of 1987 (World Commission on Environment and Development 1987), sustainability includes three dimensions: intact environment, social justice and a stable economy. Although these three dimensions already present different aspects of sustainable development, the dimension of cultural communication should be added. The world's cultural heritage and its preservation for future generations, the work on new forms of cultural expression and the dialogue of cultures in a multicultural world are not nice to have but essential for the future of humankind.

The precautionary principle is primarily applied where dangers for human health, for biodiversity and for the natural environment are at stake. In its application, all four dimensions of sustainable development have to be taken into consideration: intact environment, social justice, stable economy and cultural communication.

\section{Acknowledgement Competing interests}

The author declares that he has no financial or personal relationship(s) which may have inappropriately influenced him in writing this paper.

\section{References}

Dawkins, R., 1976, The Selfish Gene, Oxford University Press, Oxford.

De Villiers, E., 2002, 'Who will bear moral responsibility?' Communicatio 28, 16-21 from http://dx.doi.org/10.1080/02500160208537953

De Villiers, E., 2003, 'A Christian ethics of responsibility: Does it provide an adequate theoretical framework for dealing with issues of public morality?' Scriptura 82, 23-38.

De Villiers, E., 2006, 'Prospects of a Christian ethics of responsibility (Part 1): An assessment of an American version' Verbum et Ecclesia 27(2), 468-487.

De Villiers, E., 2007a, 'Prospects of a Christian ethics of responsibility (Part 2): An assessment of three German versions' Verbum et Ecclesia 28(1), 88-109.

De Villiers, E., 2007b, 'Perspektiven einer christlichen Verantwortungsethik' Zeitschrift für Evangelische Ethik 51(1), 8-23.

De Villiers, E., 2010, 'The recognition of human dignity in Africa: A Christian ethics of responsibility perspective' Scriptura 104, 163-178.

De Villiers, E., 2011a, 'An ethics of responsibility reading of Eduard Tödt's theory on the formation of moral judgements' in L. Hansen, N. Koopman, R. Vosloo (eds.) Living Theology: Essays presented to Dirk J. Smit on his sixtieth birthday, pp. 468Living Theology: Essays presente Media, Wellington.
480

De Villiers, E., 2011b, 'Prophetic witness: An appropriate mode of public discourse in the democratic South Africa?' in H. Bedford-Strohm \& E. de Villiers (eds.), Prophetic Witness: An Appropriate Contemporary Mode of Public Discourse?, pp. Prophetic Witness: An Approprid

Ethikkommission Sichere Energieversorgung 2011, Deutschlands Energiewende - Ein Gemeinschaftswerk für die Zukunft, Bundesregierung, Berlin.

European Commission, 2000, Communication on the precautionary principle of February 2, 2000, European Commission, Brussels.

European Union, 1992, 'Article 130r' in Maastricht Treaty, European Union, Maastricht.

Fox Keller, E., 2011, What is a rational response to catastrophic risk? STIAS Lecture, Stellenbosch.

Gigerenzer, G., 2007, Gut feelings: Short cuts to better decision making, Penguin Books, New York.

Gollier, C., Jullien, B. \& Treich, N., 2000, 'Scientific progress and irreversibility: An economic interpretation of the 'precautionary principle', Journal of Public Economics 75, 229-253. http://dx.doi.org/10.1016/S0047-2727(99)00052-3

Jonas, H., 1979, Das Prinzip Verantwortung: Versuch einer Ethik für die technologische Zivilisation, Insel, Frankfurt.

Jonas, H., 1984, The imperative of responsibility: In search for an ethics for the technological age, University of Chicago Press, Chicago.

Jonas, H., 1987, Der Gottesbegriff nach Auschwitz: Eine jüdische Stimme, Suhrkamp, Frankfurt.

More, M., 2010, The Perils of Precaution, viewed 06 April 2012, from www.maxmore. com/perils.htm.

Picht, G., 1980, 'Die Zeit und die Modalitäten' in G. Picht, Hier und Jetzt: Philosophieren nach Auschwitz und Hiroshima I, n.p., Klett-Cotta, Stuttgart.

Sunstein, C.R., 2005, The laws of fear: Beyond the precautionary principle, Cambridge University Press, New York. http://dx.doi.org/10.1017/CBO9780511790850

Suskind, R., 2006, The one percent doctrine. Deep inside America's pursuit of its enemies since 9/11, Simon \& Schuster, New York.

United Nations General Assembly, 1992, 'Rio Declaration on Environment and Development', in Report of the United Nations Conference on Environment and Development, Rio de Janeiro, June 03-14, 1992, viewed n.d., from http://www. un.org/documents/ga/conf151/aconf15126-1annex1.htm/

Weber, M., 1994, Wissenschaft als Beruf 1917/1919. Politik als Beruf 1919: Studienausgabe, Mohr Siebeck, Tübingen.

World Commission on Environment and Development 1987, Our Common Future, United Nations Organisation, New York. 